\title{
BMJ Open Predictors of seeking emergency medical help during overdose events in a provincial naloxone distribution programme: a retrospective analysis
}

\author{
Graham Ambrose,${ }^{1}$ Ashraf Amlani, ${ }^{1}$ Jane A Buxton ${ }^{1,2}$
}

To cite: Ambrose G, Amlani A, Buxton JA. Predictors of seeking emergency medical help during overdose events in a provincial naloxone distribution programme: a retrospective analysis. $B M J$ Open 2016;6:e011224. doi:10.1136/bmjopen-2016011224

- Prepublication history for this paper is available online. To view these files please visit the journal online (http://dx.doi.org/10.1136/ bmjopen-2016-011224).

Received 16 February 2016 Revised 19 April 2016 Accepted 20 May 2016

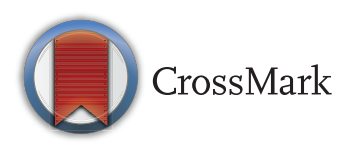

\footnotetext{
${ }^{1}$ Communicable Disease Prevention and Control Services, British Columbia Centre for Disease Control, Vancouver, British Columbia, Canada

${ }^{2}$ School of Population and Public Health, University of British Columbia, Vancouver, British Columbia, Canada
}

Correspondence to Dr Jane A Buxton; Jane.Buxton@bccdc.ca

\section{ABSTRACT}

Objectives: This study sought to identify factors that may be associated with help-seeking by witnesses during overdoses where naloxone is administered. Setting: Overdose events occurred in and were reported from the five regional health authorities across British Columbia, Canada. Naloxone administration forms completed following overdose events were submitted to the British Columbia Take Home Naloxone programme.

Participants: All 182 reported naloxone administration events, reported by adult men and women and occurring between 31 August 2012 and 31 March 2015, were considered for inclusion in the analysis. Of these, 18 were excluded: 10 events which were reported by the person who overdosed, and 8 events for which completed forms did not indicate whether or not emergency medical help was sought. Primary and secondary outcome measures: Seeking emergency medical help (calling 911), as reported by participants, was the sole outcome measure of this analysis.

Results: Medical help was sought (emergency services-911 called) in 89 (54.3\%) of 164 overdoses where naloxone was administered. The majority of administration events occurred in private residences $(50.6 \%)$ and on the street $(23.4 \%)$, where reported rates of calling 911 were $27.5 \%$ and $81.1 \%$, respectively. Overdoses occurring on the street (compared to private residence) were significantly associated with higher odds of calling 911 in multivariate analysis ( $\mathrm{OR}=10.68 ; 95 \% \mathrm{Cl} 2.83$ to $51.87 ; p<0.01)$, after adjusting for other variables. Conclusions: Overdoses occurring on the street were associated with higher odds of seeking emergency medical help by responders. Further research is needed to determine if sex and stimulant use by the person who overdosed are associated with seeking emergency medical help. The results of this study will inform interventions within the British Columbia Take Home Naloxone programme and other jurisdictions to encourage seeking emergency medical help.

\section{INTRODUCTION}

The British Columbia (BC) Take Home Naloxone (THN) programme was implemented

\section{Strengths and limitations of this study}

- To the best of our knowledge, this is the first study to identify predictors of help-seeking during overdoses within a state or provincial level naloxone distribution programme.

- Also, to the best of our knowledge, this is the first quantitative study to identify predictors of help-seeking following the administration of naloxone and to assess the possible independent effects of factors related to naloxone administration.

- Since events were reported voluntarily, study participants may differ from individuals who did not report naloxone administration events to the programme.

- Responders to overdoses may have had limited knowledge of some overdose characteristics, such as the substances used by the person who overdosed.

on 31 August 2012; it distributes naloxone kits to people who use opioids at sites across BC. ${ }^{1}$ Sites include public health units; physician offices, methadone and community health clinics; emergency departments and detoxification services. The programme consists of two essential components: (1) overdose prevention, recognition and response training that participants are required to complete in order to be eligible to obtain a kit, and (2) receiving a kit containing two ampoules of naloxone, an opioid antagonist which reverses the effects of an opioid-related overdose, two retractable syringes and other supplies (a full description is available at http://www.towardtheheart.com/naloxone). ${ }^{2}$ Kits are provided to opioid users only as naloxone is a prescription only medicine in Canada. ${ }^{1}$ At the time this analysis was conducted, the programme had trained 3132 participants and distributed 2083 kits. ${ }^{3}$ Consistent with other THN programmes, BC training emphasises seeking emergency 
medical help, by calling 911, as the first step in the response to an overdose. ${ }^{4}$

Naloxone reverses the respiratory depressant action of opioids within 2-5 min; however, its effect begins to wear off $30 \mathrm{~min}$ after administration; thus, subsequent doses of naloxone may be required for overdoses involving long-acting or high doses of opioids. ${ }^{25}$ Since 2012, BC has seen increasing rates of non-fatal and fatal overdoses involving illicit fentanyl, resulting in a province-wide public health awareness campaign in March 2015. ${ }^{6-8}$ Larger and repeat doses of naloxone may be required to successfully reverse the effects of overdoses involving high doses of fentanyl, compared to other opioids. ${ }^{9-11}$ In addition, overdoses may involve multiple substances or complex medical conditions further highlighting the importance of lay responders calling for emergency medical help. ${ }^{1} 41213$

Qualitative and quantitative studies have identified several factors which may discourage witnesses from seeking emergency medical help when responding to an overdose. Deterrents include lack of access to a phone, past negative experiences with first responders, and a respect for the 'high' of the person overdosing. ${ }^{14-17}$ Fear of police attending and the belief that the person would have or had recovered are frequently reported reasons for not seeking emergency medical help in situations both where naloxone is, and is not, avail-

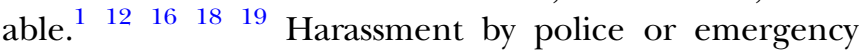
responders has been reported in some evaluations of naloxone distribution programmes. ${ }^{13} 20$

Quantitative studies have identified factors which are independently associated with calling 911 by people responding to overdoses. However, the relative importance of these predictors in overdoses where naloxone is administered is unknown. ${ }^{21} 22$ To respond to this gap in the literature, this study sought to identify factors associated with help-seeking by witnesses during overdose events where naloxone was administered.

\section{METHODS}

Sample

Naloxone kits distributed by the BC THN programme include an administration form that the kit owner is requested to complete and return to the programme following naloxone administration. Programme participants are assisted in completing and returning administration forms by site staff when they request replacement kits. Completion of the form is not required to obtain a new kit.

\section{Data collection and variables}

Information from the forms is entered into an ACCESS database. Data regarding overdose events which occurred between 31 August 2012 and 31 March 2015 were extracted during April 2015 and analysed to describe rates and predictors of seeking emergency medical help-defined as reported calling 911 during an administration event. 'Help-seeking' denotes seeking emergency medical help by calling 911 in this article. Sex and age on administration forms corresponded to the person completing the form. Age was categorised into quartiles.

Substances used by the person who overdosed, as reported by the responder, were recoded into three variables: (1) number of substances reported (1 or $>1)$; (2) stimulants; and (3) non-opioid depressants. Since at least one opioid was reported to have been involved in the majority of events $(95 \%)$, we also created a dummy variable to assess the effect of using multiple opioids ( $\leq$ one opioid or >one opioid).

Geographic location of overdose was coded by the five $\mathrm{BC}$ regional health authorities; however, three health authorities (Northern Health, Island Health and Fraser Health) were collapsed into one category because there were fewer overdoses reported in these authorities. Although Island Health, Fraser Health and Vancouver Health reported similar rates of calling 911, events occurring in the latter were coded separately as Vancouver is distinguished by its earlier adoption of harm reduction policies and by a police policy of not attending apparent overdose calls. ${ }^{23-25}$ Similar to the approach of Tobin et $a l^{22}$ we categorised the overdose setting on the basis of the level of privacy in a given setting. Private residence and hotel were considered the most private and collapsed into one 'private residence' category; 'shelter', 'supportive housing' and 'other' were considered moderately private and coded as 'other'; while 'on the street' was its own category and expected to be the least private. The question related to withdrawal symptoms on administration forms included only 'none', 'mild' and 'severe' options, which were retained as categories in this analysis. Number of naloxone doses administered was collapsed into two categories because there was only one reported event where three ampoules were administered. The programme's duration as of 31 March 2015 was divided into two equal periods of 69.4 weeks and events were coded into either the first or second half of the programme.

\section{Data analysis}

Descriptive analysis identified the number and percentages of responses for factors which were thought to be potentially associated with calling 911, based on the authors' reasoning, previous identification in the literature and input from the BC THN community advisory board meetings involving programme stakeholders. Since we were interested in the effect of age and sex of people who responded to overdoses (rather than the overdose victim), we excluded forms completed by participants who said that they had overdosed. Unadjusted ORs were computed and variables with a $\mathrm{p}$ value $\leq 0.10$ were included in the multivariate model. Logistic regression was used to assess the independent effects of potential predictor variables with the odds of a responder calling 911. 
Since some completed administration forms did not indicate if the person filling out the form had responded or had overdosed, we included a dummy variable in the multivariate model for role (responded vs not indicated) to assess the possible confounding effect of not reporting role (regardless of its $p$ value). Among those who did not indicate their role, it was unclear if sex and age responses corresponded to the person who overdosed or responded. On the basis of the small number of individuals who said they overdosed $(n=10)$, we assumed that the majority of the missing responses for role were people who responded. To test whether reporting role modified the effect of sex, we conducted a sensitivity analysis which included an interaction term between sex and role.

Some individuals reported administering naloxone multiple times. To address the possible lack of independence between administration events reported by the same individual, we allowed the logistic model's dispersion parameter to vary. In addition, we conducted a sensitivity analysis using a generalised estimating equation (GEE) on a subset of events for which an individual reporting them could be identified ( $\mathrm{n}=65$ individuals/ clusters after observations with missing data excluded). Clusters were identified on the basis of the name of the person completing the administration form, or by matching age, sex and site information. We conducted additional sensitivity analyses on subsets of observations (1) where the person admitted being the responder to the overdose, using a logistic model ( $\mathrm{n}=74$ observations after cases with missing data excluded), and (2) on observations where self-reported responders could be identified by name or other identifiers, using a GEE $(\mathrm{n}=51$ individuals/clusters after observations with missing data were excluded).

\section{RESULTS}

As of 31 March 2015, 182 administration events were reported to the programme. Of these, 18 events were excluded: 10 where the person who completed the administration form indicated that they received the naloxone, and 8 forms which did not indicate if 911 had been called. Thus, our analysis was based on 164 events; however, the response rate varied for each explanatory variable. Multivariate analysis was conducted on 102 forms where information was complete.

\section{Participant and overdose characteristics}

Of 164 participants who indicated that they either responded to the overdose $(\mathrm{n}=112)$ or did not indicate their role $(\mathrm{n}=52), 89(54.3 \%)$ reported that 911 was called. Demographics for all 164 respondents are summarised in table 1; the mean age was 40 years and $58.3 \%$ of respondents were male.

Table 2 lists characteristics of overdoses stratified by calling 911. The Vancouver Coastal Health authority accounted for the most reported administration events
Table 1 Demographic characteristics of clients who indicated whether or not 911 was called $(n=164)$

\begin{tabular}{|c|c|c|}
\hline Variable & $\begin{array}{l}\text { Number of } \\
\text { responses* }\end{array}$ & $(\%)^{\star}$ \\
\hline \multicolumn{3}{|l|}{ Sex, all participants $(n=132)$} \\
\hline Male & 77 & $58.33 \%$ \\
\hline Female & 55 & $41.67 \%$ \\
\hline \multicolumn{3}{|l|}{ Sex, responders $(n=93)$} \\
\hline Male & 56 & $60.22 \%$ \\
\hline Female & 37 & $39.78 \%$ \\
\hline \multicolumn{3}{|l|}{ Sex, role not indicated $(n=39)$} \\
\hline Male & 21 & $53.85 \%$ \\
\hline Female & 18 & $46.15 \%$ \\
\hline \multicolumn{3}{|l|}{ Age, year $(n=91)$} \\
\hline Mean, all participants (range) & 39.78 & $(20-80)$ \\
\hline Mean, responders (range) & 39.32 & $(21-80)$ \\
\hline Mean, role not indicated (range) & 40.92 & $(20-60)$ \\
\hline
\end{tabular}

(41.4\%), while only one event was reported in Northern Health. The majority of events $(50.6 \%)$ were reported to have occurred in a private residence. In the first half of the period assessed, $46.3 \%$ of those who administered naloxone called 911; in the second half, $60.6 \%$ did.

\section{Bivariate and multivariate associations}

Table 3 presents unadjusted and adjusted ORs for all variables. In the univariate analysis, the overdose occurring on the street, the responder being female, and the overdose occurring during the second half of the THN programme were associated with higher unadjusted odds of calling 911 at $\mathrm{p}<0.10$. Stimulant use by the person who overdosed, reporting mild withdrawal symptoms, and the overdose occurring in the Interior Health region were significantly associated with lower odds of calling 911 before adjusting for other variables.

In the multivariate logistic model, the setting where the overdose occurred remained significantly associated with calling 911. The odds of calling 911 were higher when the overdose occurred on the street $(\mathrm{AOR}=10.68$; 95\% CI 2.83 to 51.87) and in other settings (AOR=3.89; 95\% CI 1.03 to 16.47 ) compared to the overdose occurring in a private residence. Reported stimulant use by the person who overdosed was significantly associated with lower odds of calling 911 (AOR=0.32; 95\% CI 0.09 to 0.98 ). Being female and the overdose occurring in the Interior Health region were no longer significant. No significant associations were found between the outcome and reported withdrawal symptoms, the period of the THN programme during which the overdose occurred, and whether or not the person indicated whether they responded.

\section{Sensitivity analyses}

In the logistic model which included an interaction term between sex and role, the interaction term was non-significant $(\mathrm{p}=0.32)$ and all variables which were 
Table 2 Calling 911 by reported demographic and overdose characteristics

\begin{tabular}{|c|c|c|c|}
\hline Variable & $\begin{array}{l}\text { Number of (\%) } \\
\text { responses }\end{array}$ & $\begin{array}{l}\text { Number of }(\%) \\
\text { called } 911 \\
n=89\end{array}$ & $\begin{array}{l}\text { Number of }(\%) \\
\text { did not call } 911 \\
n=75\end{array}$ \\
\hline Age (of person completing administration form) & $91(100.00)$ & $50(54.95)$ & $41(45.05)$ \\
\hline $20-30$ & $29(31.87)$ & $18(62.07)$ & $11(37.93)$ \\
\hline $31-41$ & $16(17.58)$ & $8(50.00)$ & $8(50.00)$ \\
\hline $42-46$ & $23(25.27)$ & $16(69.57)$ & 7 (30.43) \\
\hline $47-80$ & $23(25.27)$ & $8(34.78)$ & $15(65.22)$ \\
\hline Sex (of person completing administration form) & $132(100.00)$ & $72(54.55)$ & $60(45.45)$ \\
\hline Male & 77 (58.33) & $36(46.75)$ & $41(53.25)$ \\
\hline Female & $55(41.67)$ & $36(65.45)$ & $19(34.55)$ \\
\hline Health authority & $162(100.00)$ & $88(54.32)$ & $74(45.68)$ \\
\hline Vancouver Coastal Health & $67(41.36)$ & $44(65.67)$ & $23(34.33)$ \\
\hline Interior Health & $44(27.16)$ & $10(22.73)$ & $34(77.27)$ \\
\hline Fraser Health & 39 (24.07) & 27 (69.23) & $12(30.77)$ \\
\hline Island Health & $11(6.79)$ & $7(63.64)$ & $4(36.36)$ \\
\hline Northern Health & $1(0.62)$ & $0(0.00)$ & $1(100.00)$ \\
\hline Overdose setting & $158(100.00)$ & $81(51.27)$ & $77(48.73)$ \\
\hline Private residence & $80(50.63)$ & $22(27.50)$ & $58(72.50)$ \\
\hline On the street & $37(23.42)$ & $30(81.08)$ & $7(18.92)$ \\
\hline Hotel & $14(8.86)$ & $8(57.14)$ & $6(42.86)$ \\
\hline Other & $11(6.96)$ & $7(63.64)$ & $4(36.36)$ \\
\hline Shelter & $8(5.06)$ & $8(100.00)$ & $0(0.00)$ \\
\hline Supportive housing & $8(5.06)$ & $6(75.00)$ & $2(25.00)$ \\
\hline Programme period (weeks) & $150(100.00)$ & $85(56.67)$ & $65(43.33)$ \\
\hline$<69.4$ & 41 (27.33) & $19(46.34)$ & $22(53.66)$ \\
\hline$\geq 69.4$ & $109(72.67)$ & $66(60.55)$ & $43(39.45)$ \\
\hline Number of ampoules administered & $151(100.00)$ & $82(54.30)$ & $69(45.70)$ \\
\hline 1 & $86(56.95)$ & $44(51.16)$ & $42(48.84)$ \\
\hline 2 & $64(42.38)$ & $37(57.81)$ & 27 (42.19) \\
\hline 3 & $1(0.66)$ & $1(100.00)$ & $0(0.00)$ \\
\hline Withdrawal symptoms & $139(100.00)$ & $73(52.52)$ & $66(47.48)$ \\
\hline None & $72(51.80)$ & $45(62.50)$ & $27(37.50)$ \\
\hline Mild & $47(33.81)$ & $18(38.30)$ & $29(61.70)$ \\
\hline Severe & $20(14.39)$ & $10(50.00)$ & $10(50.00)$ \\
\hline Aggression & $132(100.00)$ & $75(56.82)$ & $57(43.18)$ \\
\hline No & $105(79.55)$ & $63(60.00)$ & $42(40.00)$ \\
\hline Yes & 27 (20.45) & $12(44.44)$ & $15(55.56)$ \\
\hline Number of substances involved & $158(100.00)$ & $86(54.43)$ & $72(45.57)$ \\
\hline 1 & $85(53.80)$ & $48(56.47)$ & 37 (43.53) \\
\hline 2 & $50(31.65)$ & $31(62.00)$ & $19(38.00)$ \\
\hline 3 & $17(10.76)$ & 3 (17.65) & 14 (82.35) \\
\hline$\geq 4$ & $6(3.80)$ & $4(66.67)$ & 2 (33.33) \\
\hline Substances involved* & $158(100)$ & - & - \\
\hline Heroin & $142(89.87)$ & 78 (54.93) & $64(45.07)$ \\
\hline Fentanyl & 35 (22.15) & $18(51.43)$ & $17(48.57)$ \\
\hline Morphine & $11(6.96)$ & $5(45.45)$ & $6(54.55)$ \\
\hline Methadone & $9(5.70)$ & $2(22.22)$ & $7(77.78)$ \\
\hline Codeine & $4(2.53)$ & $0(0.00)$ & $4(100.00)$ \\
\hline Oxycodone & $4(2.53)$ & $4(100.00)$ & $0(0.00)$ \\
\hline Hydromorphone & $1(0.63)$ & $0(0.00)$ & $1(100.00)$ \\
\hline Methamphetamine & $16(10.13)$ & 7 (43.75) & $9(56.25)$ \\
\hline Cocaine & $16(10.13)$ & $5(31.25)$ & $11(68.75)$ \\
\hline Alcohol & $16(10.13)$ & $9(56.25)$ & 7 (43.75) \\
\hline Benzodiazepine & $6(3.80)$ & $4(66.67)$ & 2 (33.33) \\
\hline GHB (gamma-hydroxybutyrate) & $1(0.63)$ & $1(100.00)$ & $0(0.00)$ \\
\hline Other & $2(1.27)$ & $0(0.00)$ & $2(100.00)$ \\
\hline Role & $164(100.00)$ & $89(54.27)$ & $75(45.73)$ \\
\hline Responded & $112(68.29)$ & $64(57.14)$ & $48(42.86)$ \\
\hline Not indicated & $52(31.71)$ & $25(48.08)$ & 27 (51.92) \\
\hline
\end{tabular}


Table 3 Unadjusted and adjusted odds of Calling 911 during overdoses where naloxone is administered

\begin{tabular}{|c|c|c|c|c|c|c|}
\hline Overdose characteristics & Unadjusted OR & $95 \%$ & p Value & Adjusted OR* & $95 \% \mathrm{Cl}$ & p Value \\
\hline \multicolumn{7}{|l|}{ Age } \\
\hline $20-30$ & Ref & & & & & \\
\hline $31-40$ & 0.64 & (0.18 to 2.31$)$ & 0.50 & & & \\
\hline $41-46$ & 1.48 & (0.45 to 5.06$)$ & 0.52 & & & \\
\hline $47-80$ & 1.21 & (0.38 to 4.01$)$ & 0.75 & & & \\
\hline \multicolumn{7}{|l|}{ Sex } \\
\hline Male & Ref & & & Ref & & \\
\hline Female & 2.16 & (1.06 to 4.49$)$ & 0.04 & 2.42 & (0.88 to 7.05$)$ & 0.10 \\
\hline \multicolumn{7}{|l|}{ Health authority } \\
\hline Vancouver coastal health & Ref & & & Ref & & \\
\hline Interior health & 0.15 & $(0.06$ to 0.36$)$ & $<0.001$ & 0.30 & $(0.06$ to 1.20$)$ & 0.10 \\
\hline Other† & 1.05 & (0.48 to 2.29$)$ & 0.91 & 0.86 & (0.28 to 2.57$)$ & 0.8 \\
\hline \multicolumn{7}{|l|}{ Overdose setting } \\
\hline Private residence $\ddagger$ & Ref & & & Ref & & \\
\hline On the street & 7.26 & (3.01 to 19.74$)$ & $<0.0001$ & 10.68 & (2.83 to 51.87$)$ & $<0.01$ \\
\hline Other§ & 5.93 & (2.28 to 17.61$)$ & $<0.001$ & 3.89 & (1.03 to 16.47$)$ & 0.05 \\
\hline \multicolumn{7}{|c|}{ Person who overdosed used more than one drug } \\
\hline No & Ref & & & & & \\
\hline Yes & 0.75 & (0.39 to 1.40$)$ & 0.37 & & & \\
\hline \multicolumn{7}{|c|}{ Person who overdosed used more than one opioid } \\
\hline No & Ref & & & & & \\
\hline Yes & 0.75 & (0.36 to 1.54$)$ & 0.43 & & & \\
\hline \multicolumn{7}{|c|}{ Person who overdosed used a stimulantๆ } \\
\hline No & Ref & & & Ref & & \\
\hline Yes & 0.46 & (0.20 to 1.02$)$ & 0.06 & 0.32 & (0.09 to 0.98$)$ & 0.05 \\
\hline \multicolumn{7}{|c|}{ Person who overdosed used a depressant (other than an opioid) ${ }^{\star *}$} \\
\hline No & Ref & & & & & \\
\hline Yes & 1.25 & (0.50 3.24) & 0.63 & & & \\
\hline \multicolumn{7}{|c|}{ Naloxone programme period (weeks) } \\
\hline$<69.4$ & Ref & & & Ref & & \\
\hline$\geq 69.4$ & 1.90 & (0.91 to 4.01$)$ & 0.09 & 1.56 & $(0.41$ to 6.00$)$ & 0.51 \\
\hline \multicolumn{7}{|c|}{ No. of ampoules administered } \\
\hline$<2$ & Ref & & & & & \\
\hline$\geq 2$ & 1.28 & (0.67 to 2.47$)$ & 0.46 & & & \\
\hline \multicolumn{7}{|l|}{ Aggression } \\
\hline No & Ref & & & & & \\
\hline Yes & 0.53 & (0.22 to 1.26$)$ & 0.15 & & & \\
\hline \multicolumn{7}{|l|}{ Withdrawal symptoms } \\
\hline None & Ref & & & Ref & & \\
\hline Mild & 0.37 & (0.17 to 0.79 ) & 0.01 & 0.98 & (0.31 to 3.12$)$ & 0.97 \\
\hline Severe & 0.60 & (0.22 to 1.66$)$ & 0.32 & 0.81 & (0.21 to 3.07 ) & 0.75 \\
\hline \multicolumn{7}{|l|}{ Role } \\
\hline Responded & Ref & & & Ref & & \\
\hline Not indicated & 0.69 & (0.35 to 1.35$)$ & 0.28 & 1.81 & (0.58 to 5.86$)$ & 0.31 \\
\hline \multicolumn{7}{|c|}{$\begin{array}{l}\text { *Multivariate analysis conducted on } n=102 \text { complete cases. } \\
\text { tIncludes Northern Health, Fraser Health and Island Health. } \\
\text { tIncludes responses of 'private residence' and 'hotel'. } \\
\text { SIncludes shelter, supportive housing and responses of 'other'. } \\
\text { IIncludes methamphetamine, crack, cocaine. } \\
\text { *^Includes alcohol, benzodiazepines, GHB. }\end{array}$} \\
\hline
\end{tabular}

significant in table 3 remained so at the same level of significance. In the GEE model based on 65 individuals, the overdose occurring on the street and in other areas relative to a private residence remained highly significant $(p<0.01)$. Being female was significantly associated with calling 911 in the GEE model $(\mathrm{p}=0.03)$, while stimulant use was associated with the outcome at the same level $(p=0.07)$. The overdose occurring in Interior Health was not significant $(p=0.21)$.

In the logistic model based on the restricted sample of people who indicated that they responded $(n=74)$, the overdose occurring on the street remained associated with increased odds of calling $911(\mathrm{p}=0.01)$, but the occurrence of the overdose in the 'other' settings 
category was not $(p=0.05)$. Associations between sex and stimulant use had $p$ values of $p=0.10, p=0.09$, respectively. The effects of geographic region, withdrawal symptoms and period of overdose were non-significant. In the restricted sample GEE model ( $\mathrm{n}=51$ individuals), the odds of calling 911 were significantly higher when the overdose occurred on the street $(p<0.01)$ or in other settings $(p=0.02)$ and when the responder was female $(p=0.01)$. No other significant associations, including stimulant use $(p=0.10)$, were identified.

\section{DISCUSSION}

Our analysis found that emergency medical services were sought in $54.3 \%$ of overdoses, which falls between rates of calling 911 reported in previous studies. In their analysis of current or past drug users in Baltimore, Tobin $e t a l^{22}$ found that 911 was called in $45 \%$ of overdoses; $72 \%$ of events occurred in private residences. In a study of people who use drugs in New York City, Tracy et $a l^{21}$ found that 911 was called in $67.7 \%$ of events; $35.8 \%$ of events in this study occurred in private residences. Consistent with our results, Tracy et al found that the setting in which the overdose occurs is significantly associated with calling 911 during an overdose. They suggested that the effect may relate to a greater level of anonymity and lower risk of negative interactions with the police. ${ }^{21}$ Similarly, in interviews with people who use drugs who had received overdose response training, Lankenau $e t a l^{14}$ found that calling 911 in a public space was easier because responders and witnesses could flee the scene if necessary. They also reported one participant's concern that neighbours might see first responders at this participant's residence. ${ }^{14}$ It is also possible that people who use drugs keep illicit belongings at home or that unobserved characteristics of people who use opioids, responders or overdoses differ in private settings compared to public ones. ${ }^{26}$ Further qualitative research could elucidate other reasons why help-seeking differs in public versus private settings.

Although not significant in our main model, the effect of the sex of the responders remained significant in the generalised estimating equations. Tobin et $a t^{22}$ found that the presence of female witnesses other than the responder was independently associated with higher odds of calling 911, but found no independent effect for the responder's sex. Other research shows that attitudes towards police and willingness to call the police are influenced by past experience with police, including the perceived quality of treatment by police and the type of police intervention. ${ }^{27-32}$ Tobin $e t a l^{22}$ found that the effect of fear of arrest on calling 911 may be modified by past exposure to police during witnessed overdoses. Women are accused of fewer and different crimes than men in Canada. ${ }^{33}$ It is possible that the frequency or the nature of interactions with police differs for female responders and that women are consequently less averse to seeking help. As some social psychology research suggests, gender roles may also contribute to differences in help-seeking behaviour. ${ }^{34}$ More research is needed to understand the role of sex on help-seeking during overdoses.

Although not assessed in this study, some social variables and the responder's own overdose history could also influence help-seeking behaviour. Tobin et $a t^{22}$ found that the presence of four or more bystanders during an overdose and the responder having previously overdosed were negatively associated with calling 911. Experience witnessing a fatal overdose was positively associated with calling $911 .^{22}$ Tracy et $a l^{21}$ found that responders who had ever overdosed were less likely to seek medical help compared to those who had never overdosed. Among those who had overdosed, having gone to the hospital at their last overdose was positively associated with seeking emergency medical help. ${ }^{21}$ Future research within the programme could assess the role of these factors.

To the best of our knowledge, this is the first quantitative study to assess predictors of responders' help-seeking behaviour in the context of a state or province-level naloxone distribution programme, and the only quantitative Canadian study to assess overdose help-seeking behaviour. In addition, this was the first study to assess the effects that factors related to naloxone administration have on the likelihood of seeking medical help, although none of these were significant in the multivariate models. Recent research shows that the number of sites distributing naloxone in the USA more than tripled between 2010 and $2014 .{ }^{35}$ These results can inform the development of community-based naloxone programmes in North America and elsewhere.

The findings of this study should be interpreted in the light of several limitations. Data were self-reported and reported voluntarily. The programme is aware of considerable under-reporting, based on the number of replacement kits requested. We are aware anecdotally that some of the participants with multiple administrations do not report each administration. It is not known if overdose responders who complete administration forms differ from responders who do not complete the forms with regard to calling 911, the explanatory variables or both. Our sample included some observations where the respondent's role was not indicated. We attempted to assess the impact of missing role data on our results by controlling for role in our full sample model, by testing the role-sex interaction term and by comparing our main results with analyses conducted on a subset who said that they responded. Similar results between the full and restricted sample logistic models, and between GEE models, suggest that the magnitude of possible bias from missing role data is small; the direction of this possible source of bias is unknown. The quality of data provided on forms is also uncertain as forms may have been completed hastily and information may have been subject to recall and social desirability bias. In addition, responders to overdoses may have had limited knowledge of some 
overdose characteristics, such as substances involved in overdoses. The sample size was small and missing responses mean that multivariate analysis was conducted with only a subset of observations producing wide CIs. These limitations could impact the generalisability of our findings. However, our study is the first to evaluate predictors of help-seeking behaviour in the context of province-wide naloxone distribution programme and is not restricted to urban centres.

Our findings have several implications for the BCTHN programme and harm reduction activities in British Columbia. Programme drug alerts and other communiques distributed to stakeholders will continue to stress the importance of calling 911 during overdoses, especially in a context of rising fentanyl-related deaths. Reluctance to call 911 from private residences underscores the need to emphasise ways to call 911 , which minimise the likelihood of police attendance, such as indicating that a person is not breathing or unconscious and avoiding explicit mention of overdose. Similarly, training can recommend that participants share these strategies with their friends and family members who may be most likely to respond to an overdose or participants can encourage loved ones to attend training. In Vancouver, clients of harm reduction services can be made aware of the Vancouver Police Department's policy of not routinely attending overdose calls (only when death or violence has occurred or requested by emergency responders), which is the only policy of its kind in Canada. ${ }^{25}$ Qualitative research to understand why overdose setting and sex are associated with the likelihood of calling 911 could inform additional measures to promote help-seeking during overdoses. Lastly, at a federal level, authorities should consider legal reforms that provide immunity from drug possession or drug use charges for overdose responders, such as the 'Good Samaritan Laws' enacted in many US states. ${ }^{36}$

Acknowledgements The authors would like to thank the study participants and to acknowledge the contribution of Dr. Robert Balshaw, Senior Scientist at the $B C C D C$, who provided guidance regarding the statistical analysis.

Contributors GA contributed to the study design, performed the statistical analysis and drafted the manuscript. AA contributed to the study design and data collection, interpreted the statistical analysis, and critically reviewed and revised the manuscript. JAB contributed to the study design, interpreted the statistical analysis, and critically reviewed and revised the manuscript. All authors have read and approved the final version.

Funding This research received no specific funding from any funding agency in the public, commercial or not-for-profit sectors.

Competing interests None declared.

Ethics approval UBC Behavioural Ethics Board approval and the approval of appropriate local health research ethics boards.

Provenance and peer review Not commissioned; externally peer reviewed.

Data sharing statement No additional data are available.

Open Access This is an Open Access article distributed in accordance with the Creative Commons Attribution Non Commercial (CC BY-NC 4.0) license, which permits others to distribute, remix, adapt, build upon this work noncommercially, and license their derivative works on different terms, provided the original work is properly cited and the use is non-commercial. See: http:// creativecommons.org/licenses/by-nc/4.0/

\section{REFERENCES}

1. Oluwajenyo Banjo MPHc, Tzemis D, Al-Qutub D, et al. A quantitative and qualitative evaluation of the British Columbia take home Naloxone program. CMAJ Open 2014;2:e153-61.

2. Hoffman RS, Goldfrank LR. The poisoned patient with altered consciousness. Controversies in the use of a "coma cocktail". JAMA 1995;274:562-9.

3. Ambrose G, Buxton JA. Overdose recognition and response in the $B C$ take home Naloxone program. Vancouver, BC: BC Centre for Disease Control, 2015:4.

4. Clark AK, Wilder CM, Winstanley EL. A systematic review of community opioid overdose prevention and naloxone distribution programs. J Addict Med 2014;8:153-63.

5. Watson WA, Steele MT, Muelleman RL, et al. Opioid toxicity recurrence after an initial response to naloxone. J Toxicol Clin Toxicol 1998;36:11-17.

6. Canadian Community Epidemiology Network on Drug Use. Deaths involving Fentanyl in Canada, 2009-2014. CCENDU Bulletin, 2015.

7. Amlani A, McKee G, Khamis N, et al. Why the FUSS (Fentanyl Urine Screen Study)? A cross-sectional survey to characterize an emerging threat to people who use drugs in British Columbia, Canada. Harm Reduct J 2015;12:54

8. BC Centre for Disease Control. Fentanyl campaign launches to raise awareness about the dangers of the drug. (updated 2 March 2015; cited 15 July 2015). http://www.bccdc.ca/about/news-stories/ news-releases/2015/fentanyl-campaign-launches-to-raiseawareness-about-the-dangers-of-the-drug

9. Poklis A. Fentanyl: a review for clinical and analytical toxicologists. J Toxicol Clin Toxicol 1995;33:439-47.

10. Marquardt KA, Tharratt RS. Inhalation abuse of fentanyl Patch. J Toxicol Clin Toxicol 1994;32:75-8.

11. Schumann H, Erickson T, Thompson TM, et al. Fentanyl epidemic in Chicago, Illinois and surrounding Cook County. Clin Toxicol (Phila) 2008;46:501-6.

12. Bennett AS, Bell A, Tomedi L, et al. Characteristics of an overdose prevention, response, and naloxone distribution program in Pittsburgh and Allegheny County, Pennsylvania. J Urban Heal 2011;88:1020-30.

13. Enteen L, Bauer J, McLean R, et al. Overdose prevention and naloxone prescription for opioid users in San Francisco. J Urban Heal 2010;87:931-41.

14. Lankenau SE, Wagner KD, Silva K, et al. Injection drug users trained by overdose prevention programs: responses to witnessed overdoses. J Community Health 2013;38:133-41.

15. Sherman SG, Gann DS, Scott G, et al. A qualitative study of overdose responses among Chicago IDUs. Harm Reduct $J$ 2008;5:2.

16. Pollini RA, McCall L, Mehta SH, et al. Response to overdose among injection drug users. Am J Prev Med 2006;31:261-4.

17. Richert T. Wasted, overdosed, or beyond saving-To act or not to act? Heroin users' views, assessments, and responses to witnessed overdoses in Malmö, Sweden. Int J Drug Policy 2015;26:92-9.

18. Davidson PJ, McLean RL, Kral AH, et al. Fatal heroin-related verdose in San Francisco, 1997-2000: a case for targeted intervention. J Urban Heal 2003;80:261-73.

19. Tobin KE, Sherman SG, Beilenson P. Evaluation of the Staying Alive programme: training injection drug users to properly administer naloxone and save lives. Int J Drug Policy 2009;20:131-6.

20. Galea S, Worthington N, Piper TM. Provision of naloxone to injection drug users as an overdose prevention strategy: early evidence from a pilot study in New York City. Addict Behav 2006;31:907-12.

21. Tracy M, Piper TM, Ompad D, et al. Circumstances of witnessed drug overdose in New York City: implications for intervention. Drug Alcohol Depend 2005;79:181-90.

22. Tobin KE, Davey MA, Latkin CA. Calling emergency medical services during drug overdose: an examination of individual, social and setting correlates. Addiction 2005;100:397-404.

23. Cavalieri W, Riley D. Harm reduction in Canada: the many faces of regression. In: Pates $\mathrm{R}$, Riley $\mathrm{D}$, eds. Harm reduction in substance use and high-risk behaviour: international policy and practice. Chichester, West Sussex: Wiley-Blackwell, 2012:382-92.

24. BC Harm Reduction Strategies and Services. The History of Harm Reduction in British Columbia. (August 2012; cited 4 December 2015). http://www.bccdc.ca/resource-gallery/Documents/Educational Materials/Epid/Other/UpdatedBCHarmReductionDocumentAug2012 JAB_final.pdf 
25. Follett KM, Piscitelli A, Parkinson M, et al. Barriers to calling 9-1-1 during overdose emergencies in a Canadian context. Crit Soc Work 2014;15:18-28.

26. Klimas J, O'Reilly M, Egan M, et al. Urban overdose hotspots: a 12-month prospective study in Dublin ambulance services. Am J Emerg Med 2014;32:1168-73.

27. Cheurprakobkit S. Police-citizen contact and police performance attitudinal differences between hispanics and non-hispanics. J Crim Justice 2000;28:325-36.

28. Reisig M, Parks R. Experience, quality of life, and neighborhood context: a hierarchical analysis of satisfaction with police. Justice $Q$ 2000;17:607-30.

29. Bartsch RA, Cheurprakobkit S. The effects of amount of contact contact expectation, and contact experience with police on attitudes toward police. J Police Crim Psychol 2004; 19:58-70.

30. Smith PE, Hawkins RO. Victimization, types of citizen-police contacts, and attitudes toward the police. Law Soc Rev 1973;8:135-52.
31. Scaglion R, Condon R. Determinants of attitudes toward City police. Criminology 1980;17:485-94.

32. Jacob H. Black and white perceptions of justice in the City. Law Soc Rev 1971;6:69-90.

33. Mahony T. Women and the criminal justice system. In: Women in Canada: a gender-based statistical report. 6th edn. Statistics Canada, Ottawa, ON: Statistics Canada, Social and Aboriginal Statistics Division, 2011:169-203.

34. Eagly $\mathrm{AH}$, Crowley M. Gender and helping behavior: a meta-analytic review of the social psychological literature. Psychol Bull 1986;100:283-308.

35. Wheeler E, Jones TS, Gilbert MK. Opioid overdose prevention programs providing naloxone to laypersons-United States, 2014. MMWR Morb Mortal Wkly Rep 2015;64:631-5.

36. Davis C, Webb D, Burris S. Changing law from barrier to facilitator of opioid overdose prevention. J Law Med Ethics 2013;41 (Suppl 1):33-6. 